\title{
Incidence of Neuroimaging Abnormality in Children Presenting with New Onset Afebrile Seizures
}

\author{
R Rama Krishna Paramahamsa', Gangina Sriram ${ }^{2}$ \\ ${ }^{1}$ Associate Professor, Department of Paediatrics, GSL Medical College \& General Hospital, Rajahmundry (AP), ${ }^{2}$ Associate Professor, Department of Paediatrics, GSL \\ Medical College \& General Hospital, Rajahmundry (AP).
}

\section{Abstract}

Background: Seizures \& epilepsy affects infants \& children more than any other group. There is lack of data that has looked at Neuroimaging in all children after a first afebrile, hence the present study was planned to determine incidence of Neuroimaging abnormality in children presenting with new onset afebrile seizures. Subjects and Methods: Children in the age group of six months to sixteen years who presented to the department of Paediatrics, GSL Hospital with the symptoms of first episode of afebrile seizures were evaluated prospectively. Cases with first episode of afebrile seizures that came to pediatrics department during the period of September 2012 to July 2014 were taken. Detailed history was taken and seizures categorized according to the Classification proposed by International League Against Epilepsy (ILAE) 2006. Results: Abnormal neuroimaging is seen 60 cases (75\%)in which highest number of abnormal Neuroimaging is seen in 5-9 years(41.7\%) followed by $30 \%$ in $9-13$ years. Complex partial seizures are more common $(41.3 \%)$ followed by generalized seizures $(31.3 \%)$ in our study group. Brief seizures (<5mins) are more common which are $85 \%$ than prolonged seizures $(>15$ mins) that are of $15 \%$. Maximum affected age group in our study was age group between 5 -9 yrs $38.8 \%$ followed by $9-13$ yrs $26.6 \%$. Conclusion: Although cysticercosis incidence is greater in pork eaters, feco-oral route is also a major route of disease transmission and may also occur in population not eating pork. Cysticercosis is also more common in low socioeconomic status, poor hygiene and sanitation conditions which are evident in this study.

Keywords: Neuroimage, Afebrile seizure, Children, International League Against Epilepsy (ILAE)

Corresponding Author: Dr. Gangina Sriram, Associate Professor, Department of Paediatrics, GSL Medical College \& General Hospital, Rajahmundry (AP).

Received: September 2019

Accepted: September 2019

\section{Introduction}

Seizures are the most common Pediatric neurological disorder with 4 to $10 \%$ of children, who suffer at least one seizure in the first 16 years of life. ${ }^{[1]}$ Seizures \& epilepsy affects infants \& children more than any other group. ${ }^{[2]}$

Worldwide, it was estimated that 10.5 million children under 15 years have active seizures representing about $25 \%$ of the global seizure population. Of the 3.5 million people who develop seizures annually, $40 \%$ are younger than 15 years and more than $80 \%$ live in developing countries. ${ }^{[3]}$

The seizure incidence rates reported from India were higher and reached 60.0 per 100000 person-years. ${ }^{[4]}$ The role of neuroimaging in children presenting with first nonfebrile seizure is still not well-defined. Based on several studies, the prevalence of abnormal neuroimaging in pediatric patients with a new- onset nonfebrile seizure is estimated to be $0 \%$ to $21 \%$. ${ }^{[5,6]}$

There is lack of data that has looked at Neuroimaging in all children after a first afebrile, unprovoked seizure from developing countries, where the incidence of CNS infections are common, and causes for an apparent unprovoked afebrile seizure may be different from Western World.
Therefore, the present study was planned to determine incidence of Neuroimaging abnormality in children presenting with new onset afebrile seizures.

\section{Objectives:}

To determine the frequency of abnormal Neuroimaging in children aged between 6 months to 16 years with new onset afebrile seizures.

\section{Subjects and Methods}

Children in the age group of six months to sixteen years who presented to the department of Paediatrics, GSL Hospital with the symptoms of first episode of afebrile seizures were evaluated prospectively. Cases with first episode of afebrile seizures that came to pediatrics department during the period of September 2012 to July 2014 were taken.

\section{Inclusion criteria:}

C/O 1stepisode of afebrile seizure, Age group 6 months 16years. 


\section{Exclusion criteria:}

Past H/o seizures, Seizures with fever, Meningitis, Encephalitis, Known idiopathic case of Epilepsy/CNS malformations, Primary diagnosis other than seizures were excluded.

\section{Data collection procedure:}

Detailed history was taken and seizures categorized according to the Classification proposed by International League Against Epilepsy (ILAE)7. Thorough clinical examination was performed to detect any abnormality in the nervous system. Ex:Focal neurological deficits and also to screen the systemic disease .Diagnosis was verified by Neuroradiological tests(CT,MRI).

The purpose of this study was explained to the parents/ guardian and written consent was taken prior to the study. Data collected was kept securely and confidential by not revealing patient's basic information. An high risk consent was taken before the procedure if any needed afterduly informing to the parent's/ guardians. Permission was obtained from the Ethical Committee of GSL medical College before starting the study.

\section{Radiological images:}

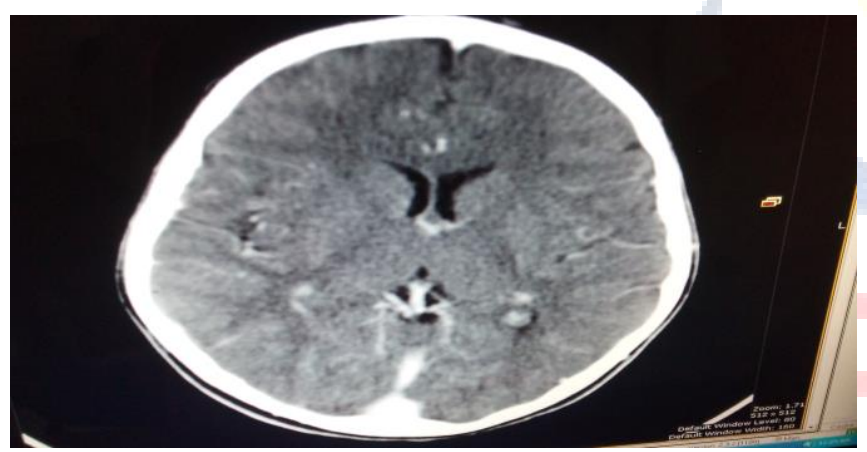

Figure 1: NEUROCYSTICERCOSIS -hypodense lesion seen in right frontal lobe $\&$ Multiple calcified granulomas noted

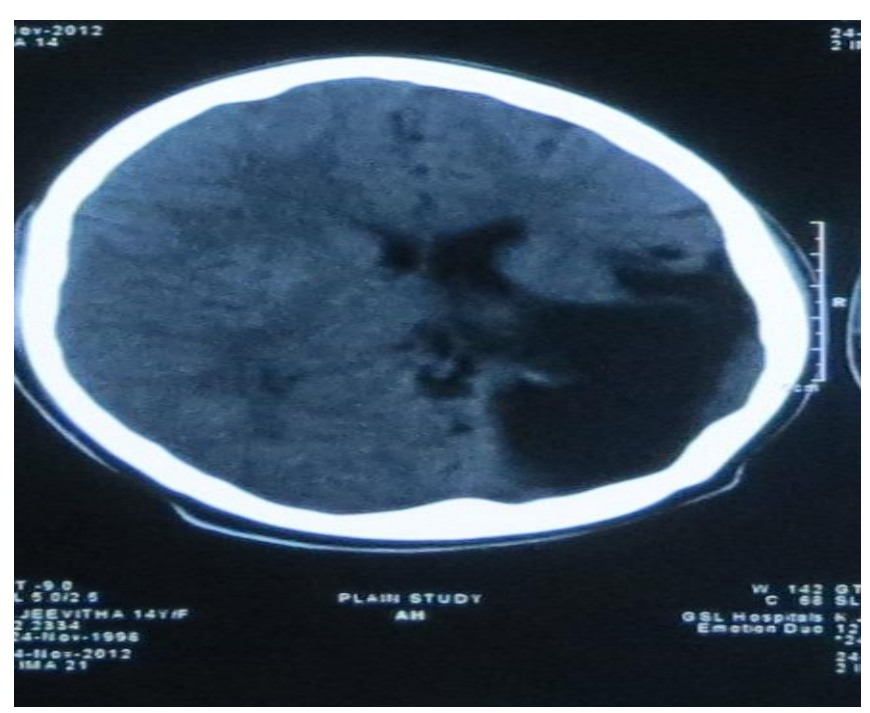

Figure 2: PORENCEPHALIC CYST in the Left occiputal lobe communicating with left occiputal horn of left ventricle.

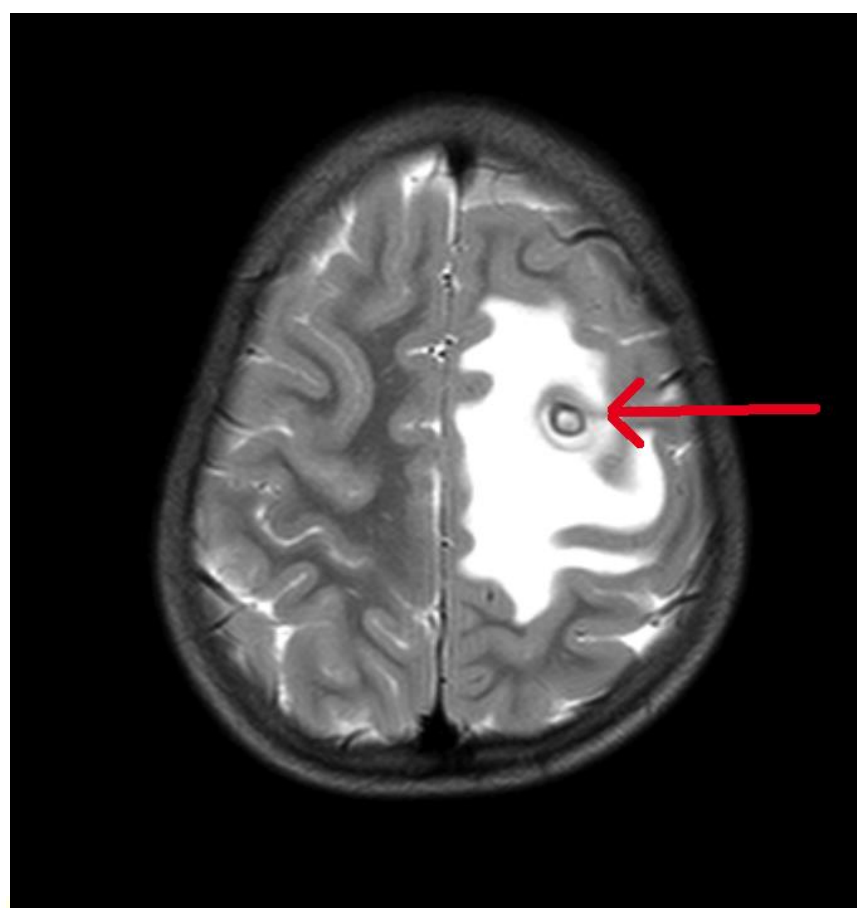

Figure 3: Well-defined ring like lesion in left frontal lobe with moderate perilesionaloedema - TUBERCULOMA.

\section{Statistical analysis:}

All the statistical analysis was performed by using SPSS-20 version and MS Excel. Variables were reported as mean \pm SD and percentage. Chi-square test was performed to determine the association between variables. $\mathrm{P}$ value of $<0.05$ was considered statistically significant.

\section{Results}

A total of 80 cases presented within one week of throwing seizures. $18(22.5 \%)$ cases were simple partial, $33(41.3 \%)$ cases were complex partial and $4(5 \%)$ cases were partial seizures with 20 generalization. 25(31.3\%)cases were generalized seizures respectively. Seizures were more on the right side. 3 cases were localized to the face. Seizures involving all the four limbs associated with loss of consciousness in $25(31.3 \%)$ cases. The CT scan shows localization to the parietal lobe in 54\% of these cases. Seizures were mainly single in number in $51(53 \%)$ cases and multiple (>2) in number in $5(8.25 \%)$ cases.

Multiple episodes of seizures were mainly due to late presentation. Case of status epilepticus was seen one (1.04\%) case due to multiple neurocysticercosis in left frontal region.

The associated symptoms were mainly headache in 25 (31\%)cases, vomiting in $22(27.5 \%)$ cases, loss of consciousness in $30(37.3 \%)$ cases, deviation of mouth in 63(78.6\%)cases. Muscle weakness in 30(31.2\%)cases and automatism in $4(5 \%)$ cases 


\section{Immunization:}

Immunization with BCG was given in total $60 \%$ cases. 10 cases show the ring enhancing lesion Only 3 cases vaccinated with BCG showed Mantoux positive (>10 $\mathrm{mm}$ )with ring enhancing lesion with anticonvulsant and anti-tuberculosis treatment.1case immunized with BCG showed an infarct on CT scan with tuberculoma.1case unimmunised with BCG and Mantoux test positive, CT was Normal.

\section{Clinical signs:}

Patients presenting with 1st episode afebrile seizures showed very few clinical signs even after a thorough neurological examination, speech abnormality, Dysarthria in $4(5 \%)$ cases, ptosis in $2(2.5 \%)$ cases, facial weakness in $12(15 \%)$ cases, raised ICT in $2(2.5 \%)$ cases. Papilloedema in $2(2.5 \%)$ cases.

\section{Investigations:}

CBP: 20cases had eosinophilia out of which Neurocysticerosis was detected on neuroimaging in 6 cases, and Tuberculoma identified in 5 cases: Remaining 9 cases had CT scan normal study.

ESR: ESR was raised in 6 cases. All these cases had other evidence of Tuberculosis, and they were started on an Antitubercular therapy with anticonvulsants.

Mantoux Test: Mantoux test was positive in 19 cases 6 cases showed ring enhancing, 1 showed an infarct and other had an obstructive hydrocephalus on CT scan.

X-ray chest: only 2 cases had paratracheal haziness and with one having tuberculous meningitis and other having a tuberculoma.

EEG: EEG was taken in 5 cases where CT scan was Normal. EEG was abnormal in 2 cases 1st was suggestive of juvenile myoclonic seizures, 2nd showed evidence of generalized epileptiform activity.

CT scan: CT scan was taken in all of the case population. It was abnormal in $60(75 \%)$ cases and normal in 20 cases (25\%).The type of lesion was Neurogranulomas in 57 cases (71.2\%), CNS tumor in 2 cases, CNS malformation (PORENCEPHALY) in 1 case

\section{Neurogranulomas:}

Neurogranulomas constitute 57 (71.2\%) cases amongst total 80 cases.

Only one case presented with status epilepticus, duration of convulsion mainly ranged from 10 to 15 minutes with the loss of consciousness from 1 to 2 hours.

History of immunization with BCG was in $60 \%$ cases. Signs of raised ICT were seen only in 2 cases. (obstructive hydrocephalus + Bil.papilloedema).

Perilesionaloedema range from absent to moderate in $97.3 \%$ case and severe in 2 cases. Size of the lesion was less than $1 \mathrm{~cm}$ in $78.4 \%$ cases. Localization of lesion was parietal in 22(58.4\%), frontal in 11(28.3\%), temporal in
$6(15 \%)$. Single lesion was seen in $34(87 \%)$ cases and multiple,i.e.,2 to 3 in $5(12.8 \%)$ cases. Only anticonvulsants were given in $24(25 \%)$ cases who showed no other evidence of tuberculosis or Neurocysticerosis. Antitubercular treatment + anticonvulsant was given in 4 cases based on other evidence of systemic tuberculosis.

These cases were followed up for a period ranging from 2 months to two years. During the study period, i.e., 21 cases did not come for followup. 59(73.75\%) cases had no problem on followup, one seizure case with raised ICT. CT scan was repeated after 6 months for 59(73.75\%) which showed partial response (calcified speck on CT/MRI) in $18(30 \%)$ cases and full resolution in $41(69.4 \%)$ cases. These 18 patients (Calcified speck on (CT/MRI) were on regular followup for any recurrence of seizures, advised using Antiepileptic drugs for two-year seizure free period.

Table 1: Clinical characteristics

\begin{tabular}{|l|l|l|}
\hline Characteristics & Frequency & Percentage \\
\hline Seizure type & & \\
\hline CPS & 33 & 41.3 \\
\hline GTCS & 25 & 31.3 \\
\hline Sec GTCS & 4 & 5.0 \\
\hline SPS & 18 & 22.5 \\
\hline Seizure duration & & \\
\hline Brief(<5mins) & 68 & 85.0 \\
\hline Prolonged(>15mins) & 12 & 15.0 \\
\hline
\end{tabular}

Out of total 80 cases, 18 (22.5\%) cases were simple partial, $33(41.3 \%)$ cases were complex partial and $4(5 \%)$ cases were partial seizures with secondary generalization. $25(31.3 \%)$ cases were generalized seizures respectively. Complex partial seizures are more common in our study group.

Brief seizures are more common (85\%) than prolonged seizures (15\%)

Table 2: Distribution of Neuroimaging cases with different parameters

\begin{tabular}{|l|l|l|l|}
\hline Parameters & Neuroimaging & Total \\
\hline & Abnormal & Normal & \\
\hline Age (year) & & & \\
\hline Upto 1 & 4 & 6 & 10 \\
\hline $1.1-5$ & 10 & 5 & 15 \\
\hline $5.1-9$ & 25 & 6 & 31 \\
\hline $9.1-13$ & 18 & 3 & 21 \\
\hline Above 13 & 3 & 0 & 3 \\
\hline Seizure Type & & & \\
\hline CPS & 25 & 8 & 33 \\
\hline GTCS & 20 & 5 & 25 \\
\hline Sec GTCS & 3 & 1 & 4 \\
\hline SPS & 12 & 6 & 18 \\
\hline Mantoux test & & & \\
\hline Negative & 43 & 18 & 61 \\
\hline Positive & 17 & 02 & 19 \\
\hline
\end{tabular}

Out of 80 cases, abnormal neuroimaging is seen 60 cases (75\%) in which highest number of abnormal Neuroimaging are seen in 5-9years (41.7\%) followed by $30 \%$ in $9-13$ years. 
Normal neuroimaging is seen in $25 \%$ cases. Significant correlation is seen between age and neuroimaging $(\mathrm{p}=<0.05)$.

Abnormal Neuroimaging observed in $60(75 \%)$ patients out of total 80 patients. Abnormal Neuroimaging observed in 37 patients $(52.54 \%)$, out of 51 patients with partial seizures. Abnormal Neuroimaging observed in 23 patient, out of 29 patients with generalized seizures.

There has been observed significant relation between mantoux testing and neuroimaging $(\mathrm{p}=<0.05)$.

\section{Table 3: NCC characteristics}

\begin{tabular}{|l|l|l|}
\hline Characteristics & Number & Percentage \\
\hline Sites & & \\
\hline Left frontal & 8 & 20.5 \\
\hline Left parietal & 13 & 33.3 \\
\hline Left temporal & 3 & 7.6 \\
\hline Right frontal & 3 & 7.6 \\
\hline Right parietal & 9 & 23.7 \\
\hline Right temporal & 3 & 7.6 \\
\hline Lesions in NCC & & \\
\hline Single & 34 & 87.2 \\
\hline Multiple & 5 & 12.8 \\
\hline Calcification & 16 & 41.0 \\
\hline Non calcified & 14 & 35.9 \\
\hline Ring enhanced & 18 & 46.2 \\
\hline
\end{tabular}

In the present study, most common site of NCC was found as Left parietal (33.3\%). Out of total 60, abnormal neuroimaging findings NCC are 39, in which single lesions are seen in 34 cases $(87.2 \%)$, multiple ( $>2$ in no) in 5 cases (12.8\%), 16 are calcified (41\%),14 are non-calcified (35.9\%) and Ring enhancement in 18 cases (46.2\%).

Table 4: Abnormal Neuroimaging causes

\begin{tabular}{|l|l|l|}
\hline Neuroimaging findings & Number & Percentage \\
\hline Astrocytoma & 1 & 1.3 \\
\hline Medulloblastoma & 1 & 1.3 \\
\hline NCC & 39 & 48.8 \\
\hline Normal & 20 & 25.0 \\
\hline Porencephaly & 1 & 1.3 \\
\hline Tuberculoma & 18 & 22.5 \\
\hline
\end{tabular}

Highest number of abnormal Neuroimaging are due to Neurocysticercosis 48.8\%, followed by Tuberculoma $22.5 \%$, CNS Tumor namely Medulloblastoma and Astrocytoma, CNS malformation namely Porencephaly.

\section{Discussion}

Approximately $4-6 \%$ of children are expected to have a seizure by the age of 16 years. The role of emergent neuroimaging for children with a new-onset afebrile seizure is not well understood, this is because the prevalence of neuroimaging abnormalities in this group has yet not been determined.

However, regarding the results reported in the literature for adults, there has been a relatively high prevalence (between $34-45 \%)$ of CT scan abnormalities in adults with a new seizure. As a result, a recommendation has been published to perform emergent neuroimaging in a large population of adults having their first seizure. ${ }^{[8]}$

So far, several studies have reported the prevalence of abnormal neuroimaging in children with new- onset seizures. The prevalence of abnormal neuroimaging in these studies ranged between $0-21 \% .^{[5]}$ The proportion of children with febrile seizures ranged between $17 \%$ and $71 \% .^{[5,6]}$ It is important to note that children with febrile seizures, either simple or complex, are at low risk of neuroimaging abnormalities. ${ }^{[9]}$ The high-risk age was reported to be less than 24 months by Adamsbaum 10 and less than 33 months by Sharma. ${ }^{[11]}$

Practice parameters, which have been recently published recommend emergent neuroimaging to be performed in a child of any age, who exhibits a postictal focal deficit (Todd's paresis) not quickly resolving, or who is not recovered to the preictal state within several hours after the seizure. ${ }^{[12]}$

Although CT scan is more available in the emergency departments, MRI is accepted as a more sensitive neuroimaging modality for children presenting with seizure.

In present study, Neuroimaging was performed in 80 patients, and abnormalities were found in $75 \%$ of cases and $25 \%$ were normal. The results showed that there was a significant relationship $(\mathrm{P}<0.05)$ between age and seizure type.

First episode afebrile seizures form $18.09 \%$ (80 patients) of the seizure cases admitted into the hospital which is the next commonest to seizures associated with fever (i.e., febrile seizures, pyogenic meningitis).

\section{Clinical Spectrum}

Afebrile seizure is a disorder occurring in the young. In our study, most patients, i.e., $38.8 \%$ belong to age group of 5-9 years. This observation is in accordance with other studies done including all age groups, which states that the majority of the patients were below the age of 20 years. In our study male $\operatorname{sex}(55 \%)$ is more affected than female sex $(45 \%)$.

In a study conducted by Chaoshuang, et al. from china found that the urban population is at a higher risk than the rural population. ${ }^{[13]}$ Similar observations were seen in urban populations in two Brazilian studies were $86.2 \%$ and $93.8 \%$ which showed urban population are at greater risk than rural population..$^{[14,15]}$ In a study conducted by Rajshekhar et al, who studied active epilepsy as an index of burden of Neurocysticercosis in Vellore district, India, found that the prevalence in urban clusters was more than twice in the rural cluster (6.23 vs. 3.04 per 1000). ${ }^{[16]}$

Contrast to the current literature and studies our study has a high percentage of rural patients $(74 \%)$, probably related to poor hygienic conditions and higher amount of fecal contamination of drinking water in the rural areas. 
Cysticercosis is a disease of low socioeconomic conditions, associated with poor hygiene and sanitation and poor safe drinking water. In a study conducted in Kerala, Kuruvilla, et al found that $73 \%$ patients belonged to low socioeconomic category. ${ }^{[17]}$ In similar two studies conducted from Chandigarh, $69 \%$ and $82.7 \%$ of the patients were of low socioeconomic strata. ${ }^{[18,19]}$ Majority $(72.5 \%)$ of the cases in the our study were of lower socioeconomic class. Hence, our results are similar to other Indian studies.

In our study out of total 80 patients, 55 were taking nonvegetarian $(70 \%), 32$ gave a history of eating pork twice or thrice. There is a significant increase in ring enhancing lesions diagnosed as Neurocysticercosis in pork eaters $(58.1 \%)(\mathrm{p}=0.02)$. Cysticercosis has been reported to be higher among non-vegetarian people, especially pork eaters. Many (27\%) of our patients were pure vegetarians, supporting the fact that feco-oral contamination is also a major route of the disease transmission. In a previous study from Chandigarh, $53.2 \%$ patients were reported as pure vegetarians. $^{[20]}$

In our study, most of the patients had complex partial $(41.3 \%)$ followed by GTCS seizures (31.3\%) in concordance with the distribution described the International League Against Epilepsy (ILAE). ${ }^{[7]}$

In our study, 51 patients had episodes of focal seizures (18SPS +33CPS) These lesions were associated with minimal symptoms of headache and vomiting in 50 patients, signs of raised ICT(papilledema) observed only in 2 cases. Similar observation was seen in Das et al. reported papilledema in $16.5 \%$ patients. ${ }^{[20]}$

These cases on follow-up over a period of two years showed good response to treatment with anticonvulsants. 32 cases had $4-5$ episodes of seizure due to late presentation. Only 2 cases showed signs of raised ICT that subsided after hospitalization. Similar excellent results were noted in Sotelo J et al. study. ${ }^{[21]}$

The commonest CT abnormality observed were Neurogranulomas namely Neurocysticercosis (49\%), and Tuberculoma (23\%) was seen in $57(71.2 \%$ ) cases in our studies comparative to $63.3 \%$ in other studies.

Most of the studies in India dealt with single lesion neurocysticercosis (solitary cysticercal granuloma). A study by Kuruvilla et al. found single lesion in $40 \%$ and multiple lesions in $60 \%$ patients. ${ }^{[17]}$ Single lesion were present in $76 \%$ and multiple lesions in $24 \%$ patients in a study by Singhi et al, ${ }^{[22]}$ Similarly, Kotokey et al, ${ }^{[23]}$ reported single lesion in $66.66 \%$ and multiple lesions in $33.33 \%$ patients, and Rajshekhar et al reported single lesion in $60.88 \%$ and multiple lesions in $39.13 \%$ patients. ${ }^{[16]}$

Most of the Latin American studies show that multiple lesion Neurocysticercosis is common in that part of the world whereas, most of the Indian studies show that single lesion Neurocysticercosis is the more common form of disease in India.

In our study lesions were mainly single (53\%) and are more common than multiple lesions, which is agreeable with most other Indian studies. Most of them 21(36\%) had lesion localized to the parietal lobe with absent to moderate perilesional edema.

Parietal lobe has been found to be the most common site of single lesion neurocysticercosis. ${ }^{[18,19,24]}$

In our study, $21(36 \%)$ of the lesions were situated in the parietal lobe. Baranwal et al. ${ }^{[18]}$ and Singhi et al. ${ }^{[19]}$ reported parietal lobe involvement in $41 \%$ and $57.3 \%$ patients, respectively.

Result of our study also shows a considerably higher proportion of neuroimaging abnormalities which include various findings such as NCC, Tuberculoma, tumor, CNS malformations.

Shipra Mathur et al study conducted in north India which showed prevalence of abnormal neuroimaging was 32\%25 although our study result was greater than this. But our study neuroimaging finding corresponds with their finding. Study conducted elsewhere reported of $8-20 \%$, but these studies were conducted in developed countries where the prevalence of tuberculosis and NCC is low. Our study results show a higher prevalence of neuroimaging abnormalities.

Most common neuroimaging abnormality observed was NCC (49\%) followed by tuberculoma(23\%) which are similar to Shipra Mathur et al which was compatible with Mayatal et al study. ${ }^{[25,26]}$

In Narendra Saini study which shows there is a significant relationship between abnormal neuroimaging and the focal seizure $(\mathrm{P}<.001)$.In their study $52.94 \%$ cases of GTCS and $83.8 \%$ cases of partial seizure have abnormal neuroimaging. Most common abnormality observed in their study was Neurocysticercosis $26.7 \%$ followed by Tuberculoma $26 \%{ }^{[27]}$ High-risk age was less than 33 months in Sharma et al.'s study and less than 24 months in Adamsbum et al.'s study. ${ }^{[10,11]}$

Berg et al reviewed 613 children with newly diagnosed epilepsy. Neuroimaging revealed a small but significant number of serious problems not previously suspected. Most of these children had partial seizures or focal EEG abnormalities. Theyhave recommended that neuroimaging should be considered during the evaluation of children with newly diagnosed epilepsy, especially for those with neurological deficits or partial seizures or focal EEG abnormalities. The study by Sharma et al, ${ }^{[11]}$ provides strong support for those conclusions of Berg et al. ${ }^{[28]}$

Various confounding factors may have direct correlation with abnormal neuroimaging finding In our study which includes low socioeconomic status, lower literacy rate, higher prevalence of tuberculosis and NCC, poor hygiene and poor nutritional status. Therefore the results of our study are not comparable to other reported studies29-31 conducted in developed countries. Where the results observed had different neuroimaging findings such as haemorrhage, brain tumor, volume reduction of cerebral hemisphere and 
vascular lesion.

In our study $50 \%$ cases of generalized seizure and $83.8 \%$ cases of partial seizure have abnormal neuroimaging, partial seizure abnormality were similar to those of George et al. ${ }^{[32]}$

This study shows no significant association between neuroimaging abnormalities and abnormal neurological examination. But Hussein et al. shows significant association. ${ }^{[30]}$ Our study results were not comparable due to higher proportion of NCC and tuberculoma cases presenting with normal neurological(CNS) examination at the time of admission.

In our study, statistical significance observed between mantoux positivity and abnormal neuroimaging $(\mathrm{P}<.05)$. D. VijayaShekaran et al showed that $21.2 \%$ mantoux test and $30.4 \%$ contact positivity were found in CNS tuberculoma. ${ }^{[33]}$ Controversies have been raised about the nature of these lesions. This was mainly based on the resolution with antituberculosis treatment. Subsequent works with biopsy studies showed that majority of these lesions representing cysticercosis in the dying form. Seizures due to NCC are increasingly reported from India. Wadia et al observed that $26 \%$ of patients with partial seizures showed NCC lesions and the rate was higher among children as $40 \%$ of his patients were below 15 years. ${ }^{[34]}$ Murthy et al reported single CT lesions in $23.4 \%$ of inpatients with all types of epilepsies. Incidence as high as $72-78 \%$ of SSRECTL has been reported after the first seizure especially in children. ${ }^{[35]}$ With aid of the CT scan, viable cysts are seen as small rounded areas of low density corresponding to the cyst fluid, without associated edema orenhancement.

The cyst wall is isodense with the brain parenchyma, and the two structures cannot be distinguished. Symptomatic parenchymal disease has evidence of inflammation on neuroimaging studies.

Patients with seizures present mostly with a less than $2 \mathrm{~cm}$ size single small ring enhancing lesion (SSRECTL) without midline shift on CT scan. This lesion needs to be differentiated from tubercular lesion which is generally bigger (>2 $\mathrm{cm}$ size) and shows occasional ventricular shift with perilesionaloedema. The MRI is superior to CT scan because it permits localization of the lesions, defines more clearly the presence of the scolex and reveals more precisely the stage of the evolution of the lesions and the type of cysticerci present. ${ }^{[36,37]}$

Enzyme linked Immunosorbent Assay (ELISA) test for cysticercus antibodies in serum and CSF is disappointing as the sensitivity $(50 \%)$ and specificity $(65 \%)$ are poor. The Enzyme linked immunoelectro transfer blot(EITB) assay using purified glycoprotein antigens from Taeniasoliumcysticerciare highly sensitive (98\%) and specific(100\%) in diagnosing neurocysticercosis, but this test is less sensitive with single lesion and calcified lesions. ${ }^{[38]}$

Focal calcification was seen in 20 cases. All the calcified granuloma was treated only with anticonvulsants.

Mass lesions were seen in 2 cases. 1 was astrocytoma in the temporal region and 2 ndis medulloblastoma in the posterior fossa, who presented with complex partial seizures. Later these 2 patients were operated where the tumors were removed and they were subjected to post operative radiotherapy.

Cerebral atrophy was observed in two cases. This was seen commonly in patients who presented with long history of seizures. First is diagnosed to be is porencephaly.

CT scan was normal in 20 patients and were treated only with anticonvulsants.

\section{Conclusion}

Although cysticercosis incidence is greater in pork eaters, feco-oral route is also a major route of disease transmission and may also occur in population not eating pork. Cysticercosis is also more common in low socioeconomic status, poor hygiene and sanitation conditions which are evident in this study.

\section{References}

1. McAbee GN, Walk JE. A Practical approach to uncomplicated seizures in children. An Fam Physicians 2000 ; 62 (5) : 1109-16

2. NICE CKS (National institute for health \& care excellence)JUNE 2009

3. Renzo Guerrini, Epilepsy in children,Lancet 2006; $367: 499$-524

4. Sawhney IM, Singh A, KaurP. A case control study and one year followup of registered epilepsy cases in a resettlement colony of North India, a developing tropical Country J NeurolSci 1999;165:31-35.

5. Landfish N, Gieon-Korthals M, Weibley RE, Panza- rino V. New onset childhood seizures.Emergency department experience.J Fla Med Assoc. 1992; 79: $679-700$.

6. Warden CR, Browstein DR, Del Baccaro MA. Pre- dictors of abnorma findings of computed tomogra- phy of the head in pediatric patients presenting with seizures. Ann Emerg Med. 1997; 29: 518 - 523.

7. Engel Jr J. ILAE classification of epilepsy syndromes. Epilepsy research. 2006 Aug 1;70:5-10.

8. Pietrzak MP, Mickel HS, Barsan WG, Greenberg MK, Goldstein ML, Byrne T, Starkman S, Stein SC, Zimmerman RD, Rosenberg JH, Alter M. Practice parameter: Neuroimaging in the emergency patient presenting with seizure (summary statement). Annals of Emergency Medicine. 1996 Jul 1;28(1):114-8.

9. Mac TL, Tran DS, Quet F, Odermatt P, Preux PM, Tan CT Epidemiology, aetiology, and clinical management of epilepsy in Asia: a systematic review. The Lancet Neurology. 2007 Jun 1;6(6):533-43.

10. Adamsbaum C, Rolland Y, Husson B. Pediatric neuroimaging emergencies. J of Neuroradiology 2004; 31 (4): 272-80.

11. Sharma S, Riviello JJ, Harper MB, Baskin MN. The role of emergent neuroimaging in children with new- onset afebrile seizures. Pediatrics 2003; 111:1-5

12. Practice parameter: evaluation of a first non-febrile seizure in children. Report of the Quality Standard Sub- committee of the American Academy of Neurology, the Child Neurology and the American Epilepsy Society. Neurology 2000; 55:616-623.

13. Chaoshuang L, Zhixin Z, Xiaohongk W, Zhanlian H, Zhiliang G. Clinical analysis of 52 cases of neurocysticercosis. Trop Doct 2008;38:192-4.

14. Das Chagas MG, D'OliveiraJúnior A, Tavares-Neto J. Clinical aspects of neurocysticercosis at semi-desert region of Brazilian northeast. ArqNeuropsiquiatr 2003;61:398-402. 


\section{Paramahamsa \& Sriram; Neuraimaging Alenarmality in Children}

15. Benedeti MR, Falavigna DL, Falavigna-Guilherme AL, Araújo SM. Epidemiological and clinical profile of neurocysticercosis patients assisted by the Hospital Universitário Regional de Maringá, Paraná, Brazil. ArqNeuropsiquiatr 2007;65:124-9.

16. Rajshekhar V, Raghava MV, Prabhakaran V, Oommen A, Muliyil J. Active epilepsy as an index of burden of neurocysticercosis in Vellore district, India. Neurology 2006;67:2135-9.

17. Kuruvilla A, Pandian JD, Nair M, Radhakrishnan VV, Joseph S. Neurocysticercosis:A Clinical and Radiological Appraisal from Kerala State, South India. Singapore Med J 2001;42:297-303.

18. Baranwal AK, Singhi PD, Khandelwal N, Singhi SC. Albendazole therapy in children with focal seizures and single small enhancing computerized tomographic lesions: A randomized, placebo controlled, double blind trial. Pediatr Infect Dis J 1998;17:696-700.

19. Singhi P, Dayal D, Khandelwal N. One week versus four weeks of albendazole therapy for neurocysticercosis in children: A randomized, placebo controlled double blind trial. Pedi Infect Dis J 2003;22:268-72.

20. Das RR, Jain S, Maheshwari MC. Neurocysticercosis: An analysis of 206 cases from an Indian hospital. Ann IndAcadNeurol 2001;4:95-8.

21. Roman G,Sotelo J, Del Brutto et al .A proposal to declare neurocysticercosis an international reportable disease. Bull World Health Organ 2007;78: 399-406.

22. Singhi P, Ray M, Singhi S, Khandelwal N. Clinical spectrum of 500 children with neurocysticercosis and response to albendazole therapy. J Child Neurol 2000;15:207-13

23. Kotokey RK, Lynrah KG, De A. A clinico-serological study of neurocysticercosis in patients with ring enhancing lesions in CT scan of brain J Assoc Physicians India 2006;54:366-70.

24. Gogia S, Talukdar B, Choudhury V. Neurocysticercosis in children: Clinical findings and response to albendazole therapy in a randomized, double blind, placebo controlled trial in newly diagnosed cases. Trans R Soc Trop Med Hyg 2003;97:416-21.

25. ShipraMathur, Kevin Southern : Significant Findings on Cranial CT Scan After a First Unprovoked Seizure in Children from North India J Trop Pediatr. 2007;53 (6): 428-430

26. Maytal J, Krauss J M, Novak G, Nagelberg J, Patel M. The role of brain computed tomography in children with seizures in the emergency department. Epilepsia 2000; 84: 390-2.

27. Narendra Saini, Anamika Baghel. Neuroimaging Abnormalities In Children With First Afebrile Seizure IOSR J. Dental Med. Sci.2013;5(5):21-24

28. Berg AT, Testa FM, Levy SR, Shinnar S. Neu- roimaging in children with newly diagnosed epilepsy: a community based study. Pediatrics 2000; 106-257-532.

29. Simone Carreiro Vieira; Paulo Breno Noronha Liberalesso : First unprovoked seizure: clinical and electrographic aspects. Epilepsy clin.neurophysiol. vol.12 no.2 Porto Alegre June 2006.

30. Hussein I Alawneh Hussein A Bataineh : Urgent Neuroimaging In Children With First Nonfebrile Seizures. Middle Eat Jr. of Family Medicine. January 2008 - Volume 6 Issue.

1. 31. Sujit Sharma, James J. Riviello, Marvin B. Harper, and Marc N. Baskin: The Role of Emergent Neuroimaging in Children With New- Onset Afebrile Seizures official journal of the Ameracanacedamy of pediatrics $111 ; 1,2003$

31. George H Swingler, Anthony T R Westwood, Karen Iloni : The utility of computed tomography for recent-onset partial seizures in childhood S Afr Med J 2006; 96: 941-944.

32. D. Vijayashekharan, R. Arvind Kumar: Mantoux and contact positivity in Tuberculosis. IJP. 2006;73.

33. WadiaRS,Makhale CN, KelkarAV,Focal epilepsy in India with specialreferenceto lesions showing ring or disc like enhancement on contrast CT J NeurosurgPsychiatr 1987;50:1298-1301

34. Murthy JMK,Subba Reddy YV.Prognosis of epilepsy associated with single CT enhancing lesion : A long term follow up study.JNeurolSci1998;159:151-155.

35. Garg R K, Nag D. Single ring or disc enhancing CT lesion in Indian children and adolescents after single seizures(letter).Arch Pediatr Adolesc Med1997;157:632-634

36. Garcia HH, Del Brutto, New concepts in the diagnosis and management of Neurocysticercosis, Am.J.Trop.Med.Hyg.2005,Pg 3-9.

37. Schantz P M, Sarti,E, Lancarte A. Community based Epidemiological Investigations of Cysticercosis due to Tenia Solium: Comparison of serological screening tests and clinical findings in two populations in Mexico. Clin infect Dis 1994;18:879.

Copyright: (C) the author(s), 2019. It is an open-access article distributed under the terms of the Creative Commons Attribution License (CC BY 4.0), which permits authors to retain ownership of the copyright for their content, and allow anyone to download, reuse, reprint, modify, distribute and/or copy the content as long as the original authors and source are cited.

How to cite this article: Paramahamsa RRK, Sriram G. Incidence of Neuroimaging Abnormality in Children Presenting with New Onset Afebrile Seizures. Asian J. Clin. Pediatr. Neonatol.2019;7(3):34-40.

DOI: dx.doi.org/10.21276/ajcpn.2019.7.3.10

Source of Support: Nil, Conflict of Interest: None declared. 